\title{
Grewia spp. Biopolymer as Low-Cost Biosorbent for Hexavalent Chromium Removal
}

\author{
G. P. Kofa $\mathbb{D}^{1},{ }^{1}$ G. R. Nkoue Ndongo, ${ }^{2}$ M. B. Kameni Ngounou, ${ }^{1}$ M. N. Nsoe, ${ }^{1}$ E. V. Amba, ${ }^{1}$ \\ and S. Ndi Koungou ${ }^{1}$ \\ ${ }^{1}$ Water Treatment and Filtration Research (Chem. Eng.) Group, Department of Process Engineering, ENSAI, \\ University of Ngaoundere, P.O. Box 455, Ngaoundere, Cameroon \\ ${ }^{2}$ Faculty of Science, University of Douala, P.O. Box 24157, Douala, Cameroon
}

Correspondence should be addressed to G. P. Kofa; guikofa@yahoo.fr

Received 28 December 2018; Accepted 10 March 2019; Published 15 May 2019

Academic Editor: Claudio Cameselle

Copyright (c) 2019 G. P. Kofa et al. This is an open access article distributed under the Creative Commons Attribution License, which permits unrestricted use, distribution, and reproduction in any medium, provided the original work is properly cited.

In this study, Grewia spp. biopolymer was utilized as a biosorbent for elimination of hexavalent chromium from water. Fouriertransform infrared spectrometry (FTIR) and X-ray diffraction (XRD) were performed for characterization of the biosorbent. Experiments were conducted in a batch mode at room temperature $\left(25 \pm 2^{\circ} \mathrm{C}\right)$ and agitation speed of $100 \mathrm{rpm}$ to determine the influence of biosorbent dose, contact time, $\mathrm{Cr}(\mathrm{VI})$ concentration, and initial solution $\mathrm{pH}$. It was found that equilibrium was attained in $50 \mathrm{~min}$. A pseudo-first-order model suited well than a pseudo-second-order model. Biosorption capacity of Grewia spp. biopolymer increased with increase in concentration and depended on the solution pH. Langmuir and Freundlich models described experimental data very well. These findings showed that Grewia spp. biopolymer can serve as a biosorbent for elimination of $\mathrm{Cr}(\mathrm{VI})$ from water.

\section{Introduction}

Water polluted with heavy metals has become a serious environmental problem [1]. Chromium is one of such heavy metals. Its presence in water originates from some anthropogenic source including industrial activities such as dyeing, electroplating, textile processing, alloying, and fertilizer production [2-4]. Chromium in aqueous solution exists in two oxidation states, trivalent state $[\mathrm{Cr}(\mathrm{III})]$ and hexavalent state $[\mathrm{Cr}(\mathrm{VI})]$. The trivalent chromium is an essential trace element for metabolism in mammals (for living organisms), while the hexavalent is more dangerous because of its carcinogenic effects in mammals [5]. Therefore, elimination of $\mathrm{Cr}(\mathrm{VI})$ from water or at least its reduction below the maximum allowed limit is necessary. The technologies used for the treatment of waters contaminated by chromium are ion exchange, membrane separation, coagulation, adsorption, and solvent extraction [6]. However, these methods have technological and economical limitations [7, 8]. Therefore, cost-effective treatment for chromium elimination is required especially in developing countries. Adsorption using biological materials is one of the recommended processes because it has many advantages including low cost, minimization of chemicals, and possession of great adsorption efficiency [9, 10]. Many biological materials (biosorbents) such as gum kondagogu [11] and brown algae Pelvetia canaliculata [12] have efficiently eliminated chromium from water. The efficiency of this process is attributed to the presence of some chemical groups like carboxyl and hydroxyl in the biosorbent. These groups are responsible for physical and chemical interactions of heavy metals with the biosorbent [13]. Grewia spp. is widespread in some northern regions of Cameroon. This plant is used by the population in the clarification of water wells and a local beer (bilibili). Biopolymer extracted from Grewia spp. contains chemical groups mentioned above that are involved in metal binding $[14,15]$. Thus, it can be used for hexavalent chromium elimination from water.

The aim of this study is then to investigate the feasibility of Grewia spp. biopolymer as a biosorbent for elimination of 
chromium (VI) by varying contact time, solution $\mathrm{pH}$, biosorbent dose, and chromium concentration. Kinetics and isotherm studies were also performed.

\section{Materials and Methods}

2.1. Materials. Grewia spp. biopolymer barks were collected from Mokolo, a locality in the northern region of Cameroon, transported to the laboratory, and dried and stored at room temperature. Crude Grewia gum was obtained following the method of Somboonpanyakul et al. [16]. The dried and pulverized bark of Grewia spp. was dispersed in distilled water $(1: 80 \mathrm{w} / \mathrm{v}, \mathrm{pH} 4)$ at $50^{\circ} \mathrm{C}$ for 4 hours. The fibrous material from the dispersed mucilage was removed by centrifugation at $5300 \mathrm{rpm}$ for $20 \mathrm{~min}$ at $4^{\circ} \mathrm{C}$. Thereafter, the crude mucilage was precipitated with 3 volumes of $95 \%$ absolute ethanol and freeze-dried.

All other reagents used in this study were of analytical grade. A synthetic solution of $\mathrm{Cr}(\mathrm{VI})$ was obtained by dissolving appropriate quantity of potassium dichromate powder (Riedel-de Haën) in distilled water.

\subsection{Characterization of Biosorbent}

2.2.1. Fourier-Transform Infrared Spectroscopy (FTIR). The identification of chemical groups on the surface of Grewia spp. biopolymer powder was performed by Fouriertransform infra-red spectrometer (Bruker Vertex 70). Approximately $1 \mathrm{mg}$ of the sample was mixed with $25 \mathrm{mg} \mathrm{KBr}$, and both were ground together in a ceramic mortar. Thereafter, a pellet was prepared using a 5-ton press and analyzed by an infrared spectrometer. The spectra were recorded in the $4000 \mathrm{~cm}^{-1}$ to $400 \mathrm{~cm}^{-1}$ wavenumber range with ten scans collected at $4 \mathrm{~cm}^{-1}$ resolution.

2.2.2. Powder X-Ray Diffraction. X-ray diffraction was carried out on Desktop X-ray Diffractometer Rigaku, MiniFlex II. Samples were analyzed over an angular range of 2 theta $\left(10^{\circ}-90^{\circ}\right)$.

2.2.3. Zeta Potential. Electrokinetic zeta potential (ZP) of Grewia spp. biopolymer was measured as a function of $\mathrm{pH}$ using dynamic light scattering (DLS) with the nanoparticle analyzer SZ-100 (Horiba Scientific).

2.3. Biosorption Experiments. The biosorption experiments were realized in a batch mode using $100 \mathrm{~mL}$ Erlenmeyer flasks fixed to a shaker, Polystest 20 (Bioblock Scientific). About $50 \mathrm{~mL}$ of chromium solution was poured into Erlenmeyer flasks, and the $\mathrm{pH}$ of the solution in each flask was adjusted to the desired value with either $0.1 \mathrm{M} \mathrm{HCl}$ or $0.1 \mathrm{M} \mathrm{NaOH}$. A predetermined amount of biosorbent was then added to each flask, fixed on a shaker, and set on agitation at a speed of $100 \mathrm{rpm}$. After a given time, the shaker was stopped and the flasks removed. The suspensions were centrifuged at $5000 \mathrm{~g}$, and the supernatant was recovered. The supernatant absorbance was measured using the spectrophotometer (Jenway 7310, UK) at $540 \mathrm{~nm}$ after complexation using the diphenylcarbazide solution as described by Clesceri et al. [17].

The amount of chromium sorbed at time " $t$ " and the percentage of chromium elimination were calculated according to the following equations:

$$
q_{t}=\frac{\left(C_{\mathrm{i}}-C_{t}\right)}{m} V
$$

where $C_{\mathrm{i}}(\mathrm{mg} / \mathrm{L})$ is the initial concentration of $\mathrm{Cr}(\mathrm{VI}), C_{t}$ $(\mathrm{mg} / \mathrm{L})$ is the concentration of $\mathrm{Cr}(\mathrm{VI})$ at contact time $t$ ( $\mathrm{min}), V(\mathrm{~L})$ is the volume $\mathrm{Cr}(\mathrm{VI})$ solution, and $m(\mathrm{~g})$ is the amount of the biosorbent added.

Elimination efficiency of $\mathrm{Cr}(\mathrm{VI})$ was determined by the following equation:

$$
\% R=\frac{\left(C_{\mathrm{i}}-C_{\mathrm{e}}\right)}{C_{\mathrm{i}}} 100,
$$

where $C_{\mathrm{i}}$ and $C_{\mathrm{e}}$ are the initial and the equilibrium concentration $(\mathrm{mg} / \mathrm{L})$ of $\mathrm{Cr}(\mathrm{VI})$, respectively.

\section{Results and Discussion}

\subsection{Characteristics of Biosorbent}

3.1.1. X-Ray Analysis of Grewia spp. Biopolymer. XRD analysis was applied to detect the crystallinity of the Grewia spp. biopolymer. The XRD pattern showed zero peak characteristics; Grewia spp. biopolymer consists of amorphous structure (Figure 1). This suggests that chromium (IV) ion can easily penetrate into the surface of the biopolymer [18].

3.1.2. Functional Groups Determination by FTIR. The FTIR spectrum of Grewia spp. biopolymer before and after chromium biosorption is presented in Figure 2. In all spectrum sorption bands, free water was observed to be around $3300 \mathrm{~cm}^{-1}$. The intensity of the peak engaged by free water molecules was found diminished little with the biosorption of $\mathrm{Cr}(\mathrm{VI})$ on the Grewia biopolymer. This suggests that, the biosorption may happen on $-\mathrm{OH}$ bending of water, the inner surface - $\mathrm{OH}$ stretching vibration. The important decrease of peak intensity was also observed for the bands of $1049,1728,1418$, and $1595 \mathrm{~cm}^{-1}$ after adsorption. All those changes can be attributed to the engagement of some chemical groups of Grewia such as $\mathrm{CONH}$ and $\mathrm{COOH}$ (uronic acid) during the biosorption.

3.1.3. Nature of Charge of Grewia spp. Biopolymer. The ZP is the potential of shear plane of the particle when it moves in liquid. ZP was measured to collect information on the stability and charge behavior of the polymer. The ZP of Grewia spp. biopolymer in the aqueous medium were recorded and found to be $-30.45 \pm 0.48 \mathrm{mV},-24.64 \pm 0.49 \mathrm{mV}$, and $-18.96 \pm 0.66 \mathrm{mV}$ at $\mathrm{pH}$ value of 9,7 , and 5 , respectively (Figure 3). These results showed that, the Grewia spp. biopolymer is anionic in nature and can be attributed to the existence of uronic acids as previously showed FTIR spectral. 


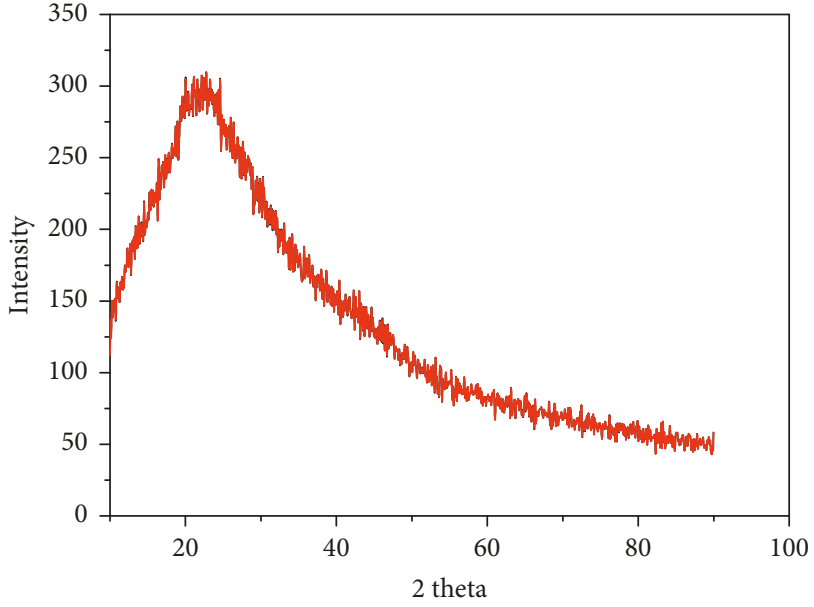

Figure 1: X-ray diffraction (XRD) pattern of Grewia spp. biopolymer.

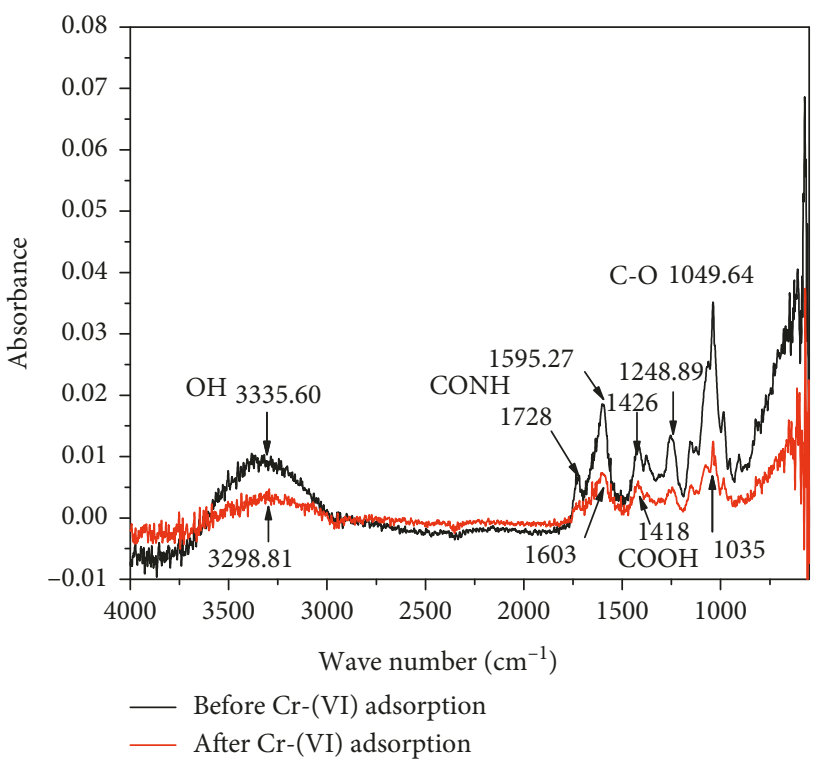

FIgURE 2: FTIR spectra of Grewia spp. biopolymer.

3.2. Effect of Biosorbent Mass. The effect of biosorbent mass on the biosorption of $\mathrm{Cr}(\mathrm{VI})$ was studied. The amount of the biosorbent used varied from $0.1 \mathrm{~g}$ to $1 \mathrm{~g}$, while other parameters such as $\mathrm{pH}$, agitation time, and agitation speed were kept constant. The biosorbent dose affects the extent of chromium as shown in Figure 4. The extent of chromium elimination varied from $47 \%$ to $98 \%$, respectively, at $0.1 \mathrm{~g} / \mathrm{L}$ and $0.8 \mathrm{~g} / \mathrm{L}$. The increase in chromium biosorption with increase of biopolymer dose may be due to the availability of higher surface area for chromium biosorption [19]. However, there was no noticeable variation in the extent of $\mathrm{Cr}(\mathrm{VI})$ adsorption above $0.8 \mathrm{~g} / \mathrm{L}$. This may be due to nonadsorbability of $\mathrm{Cr}(\mathrm{VI})$ ions as a result of sorbent-sorbate interaction [20]. Additionally, at high dose, the biosorbent also adhere to each other, consequently adsorption extent becomes constant, due to the fact that all the surface area is not available.

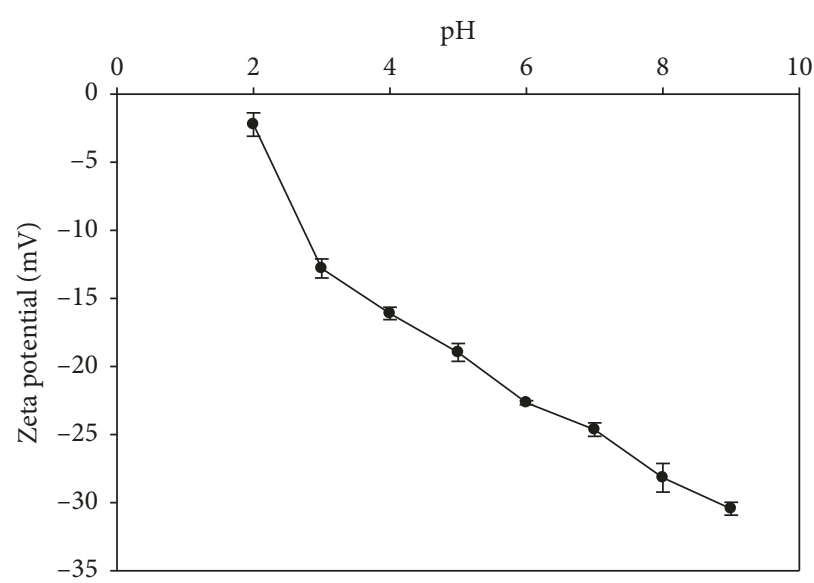

FIgURE 3: Zeta potential of Grewia spp. powder at different $\mathrm{pH}$.

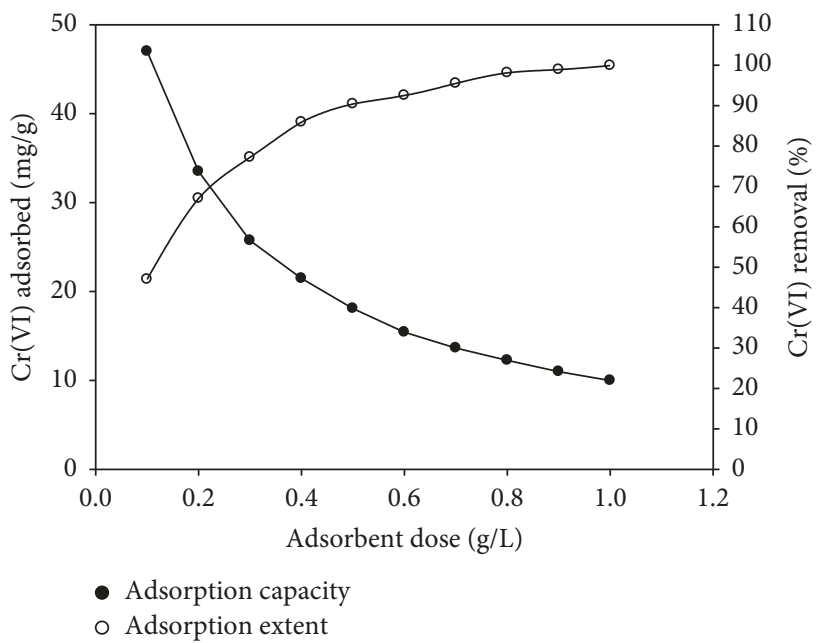

Figure 4: Effect of biosorbent mass on the biosorption of $\mathrm{Cr}(\mathrm{VI})$ ions onto biopolymer at $\mathrm{pH} 7 \pm 0.05, T=25 \pm 2^{\circ} \mathrm{C}$, and initial concentration $10 \mathrm{mg} / \mathrm{L}$.

When the mass is low, all biosorbent sites are occupied and the surface is saturated, resulting in a high value of the amount of chromium adsorbed.

3.3. Effect of Contact Time. The effect of contact time on $\mathrm{Cr}(\mathrm{VI})$ biosorption on Grewia spp. polymer was studied. It is observed that (Figure 5), as contact time increases, the amount of chromium biosorbed increases initially, afterwards it gradually approaches a constant value denoting attainment of equilibrium; this is independent of the $\mathrm{pH}$ studied. The rate of $\mathrm{Cr}(\mathrm{VI})$ biosorption is high in the initial $40 \mathrm{~min}$, thereafter level off and approaches zero. These variations in the rate of biosorption may be due to the fact that, initially, all sorption sites were vacant and the solute concentration gradient was high. Afterwards, the chromium rate decreases due to decrease in sorption sites [20]. For other studies, 60 minutes was chosen as the equilibrium time. 


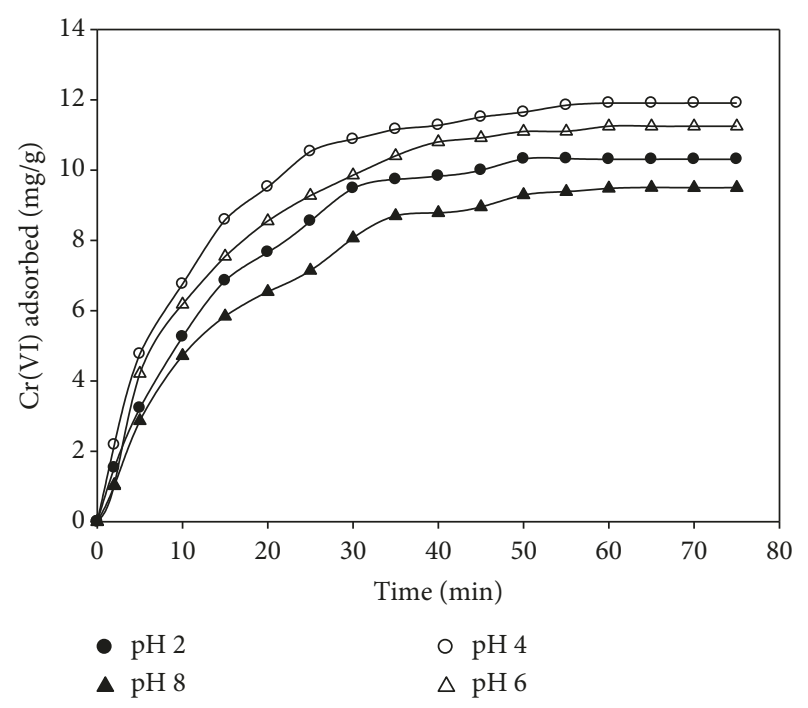

Figure 5: Effect of contact time at different pH. Biosorbent dose $=$ $0.8 \mathrm{~g} / \mathrm{L} ; T=25 \pm 2^{\circ} \mathrm{C}$; initial $\mathrm{Cr}(\mathrm{VI})$ concentration $=10 \mathrm{mg} / \mathrm{L}$.

3.4. Effect of Chromium Initial Concentration. The experiments were carried out at different chromium concentrations $(20,40,60,80$, and $100 \mathrm{mg} / \mathrm{L})$ and a contact time of $60 \mathrm{~min}$. The amount of $\mathrm{Cr}(\mathrm{VI})$ ion biosorbed on the biopolymer powder is presented in Figure 6. It can be observed from this figure that by increasing initial chromium (VI) concentration, biosorption capacity is also increased. This is due to the increase in the driving force of the concentration gradient [21]. Similar trend of $\mathrm{Cr}(\mathrm{VI})$ adsorption onto the biosorbent as function of initial concentration has also been reported by other studies [22-24].

3.5. Effect of $p H$. The process of biosorption depends on the $\mathrm{pH}$ of the solution as it affects the surface charge of biosorbent and the degree of ionization and specification of the absorbate [25]. The $\mathrm{pH}$ of solution was varied from 2 to 8 . From Figure 7, it was observed that the amount of $\mathrm{Cr}(\mathrm{VI})$ adsorbed increased with the increase of $\mathrm{pH}$. The maximum $\mathrm{Cr}(\mathrm{VI})$ biosorbed was found around $\mathrm{pH}$ 4. The increase of the amount of chromium biosorbed with increasing $\mathrm{pH}$ can be attributed to the decline in competition between the proton and metal for the active sites, which results in a lower electrostatic repulsion between the surface and metal ions $[1,26]$. As the $\mathrm{pH}$ increased, the protonation gradually weakened, and in alkaline solutions, the $\mathrm{OH}^{-}$ions competes with $\mathrm{Cr}(\mathrm{VI})$ anionic species [27]. As consequence low amount of chromium adsorbed was observed at high $\mathrm{pH}$ values.

3.6. Biosorption Kinetics. In order to evaluate the kinetic mechanism that controls the biosorption process, the pseudo-first-order and pseudo-second-order models were applied to experimental data.

The pseudo-first-order model is given as follows [28]:

$$
\log \left(q_{\mathrm{e}}-q_{t}\right)=\log q_{\mathrm{e}}-\frac{k_{1}}{2.303} t
$$

where $q_{t}(\mathrm{mg} / \mathrm{g})$ is the amount of chromium biosorbed at time $t, k_{1}\left(\mathrm{~min}^{-1}\right)$ is the rate constant of the first-order

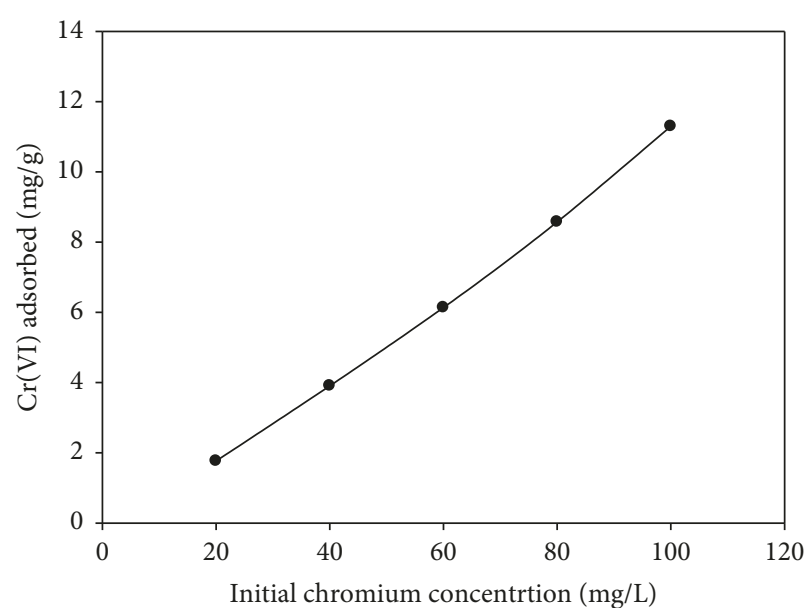

FIgURE 6: Effect of initial chromium concentration. $\mathrm{pH} 7 \pm 0.05$; $T=25 \pm 2^{\circ} \mathrm{C}$.

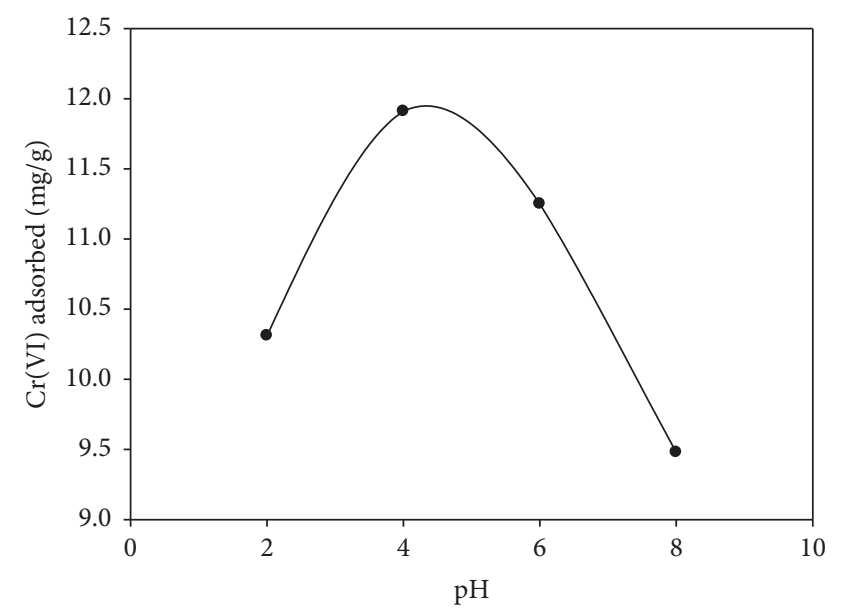

Figure 7: Effect of initial solution pH. $\mathrm{Cr}(\mathrm{VI})$ concentration $=10 \mathrm{mg} / \mathrm{L} ; T=25 \pm 2^{\circ} \mathrm{C}$.

reaction, and $q_{\mathrm{e}}$ the equilibrium sorption uptake derived from extrapolation of experimental data at time $t=$ infinity. A plot of $\log \left(q_{\mathrm{e}}-q_{\mathrm{t}}\right)$ versus $t$ is presented in Figure 8(a) $q_{\mathrm{e}}$ and $k_{1}$ are determined and presented in Table 1 .

The pseudo-second-order kinetic model [28] is expressed as follows:

$$
\frac{t}{q_{t}}=\frac{1}{k_{2} q_{\mathrm{e}}^{2}}+\frac{1}{q_{\mathrm{e}}} t .
$$

The plot of $t / q_{t}$ versus $t$ is presented in Figure 8(b) and $q_{t}$ and $k_{2}$ were determined (Table 1).

From Table 1, the values of correlation coefficients obtained for the pseudo-first-order and pseudo-secondorder reactions were all above 0.90 . However, the biosorption capacities calculated by pseudo-first-order model are close to those determined by experiments. That means, the pseudo-first-order model is appropriate to describe hexavalent chromium biosorption on Grewia spp. biopolymer, implying that sorption is of physical nature involving weak forces such as van der Waals bonding $[29,30]$. The first-order adsorption rate decreases with increased $\mathrm{pH}$, indicating that $\mathrm{Cr}(\mathrm{VI})$ biosorption is favorable at acidic $\mathrm{pH}$. 


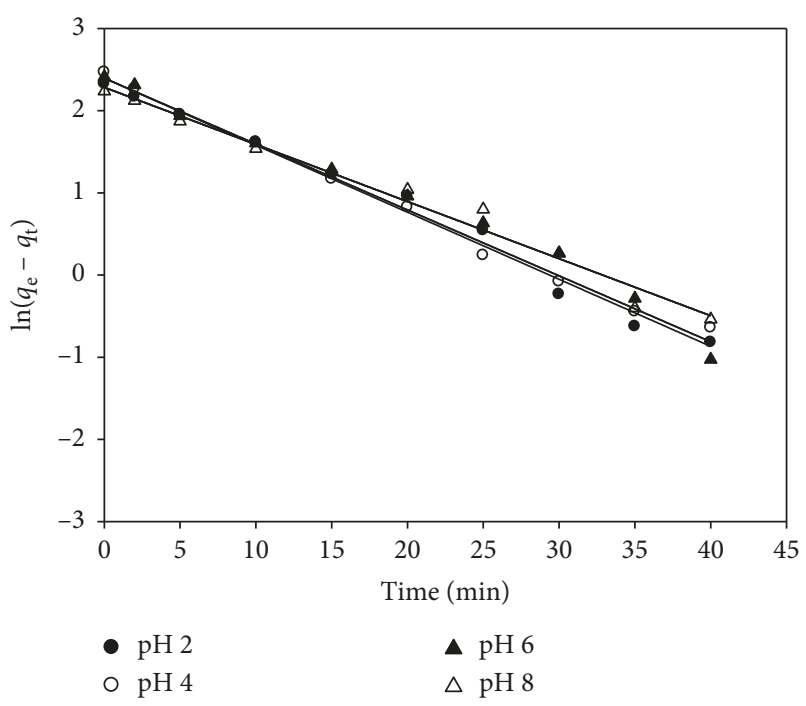

(a)

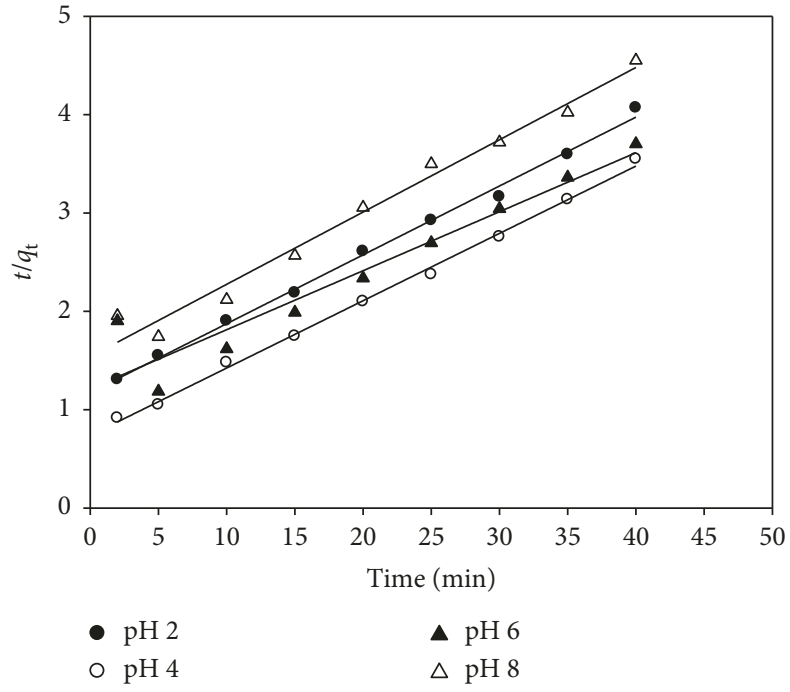

(b)

Figure 8: First-order (a) and second-order kinetics (b) modeling of $\mathrm{Cr}(\mathrm{VI})$ biosorption on Grewia spp. biopolymer. Biosorbent dose: $0.8 \mathrm{~g} / \mathrm{L}$, $T=25 \pm 2^{\circ} \mathrm{C}$.

TABLE 1: Kinetics parameters for Cr(VI) biosorption on Grewia spp. biopolymer.

\begin{tabular}{|c|c|c|c|c|c|c|c|}
\hline \multirow{2}{*}{ Initial $\mathrm{pH}$ of the solution } & \multicolumn{4}{|c|}{ First-order model } & \multicolumn{3}{|c|}{ Second-order model } \\
\hline & $q_{\mathrm{e}, \exp }(\mathrm{mg} / \mathrm{g})$ & $k_{1}\left(\min ^{-1}\right)$ & $q_{\mathrm{e}, \mathrm{cal}}(\mathrm{mg} / \mathrm{g})$ & $R^{2}$ & $k_{2}\left(\mathrm{~g} \cdot \mathrm{mg}^{-1} \cdot \min ^{-1}\right)$ & $q_{\mathrm{e}, \mathrm{cal}}(\mathrm{mg} / \mathrm{g})$ & $R^{2}$ \\
\hline 2 & 10.268 & 0.1879 & 10.478 & 0.9875 & 0.0041 & 14.285 & 0.9963 \\
\hline 4 & 11.803 & 0.1847 & 10.974 & 0.9941 & 0.0063 & 14.598 & 0.9973 \\
\hline 6 & 11.159 & 0.1828 & 11.652 & 0.9836 & 0.0030 & 16.667 & 0.9107 \\
\hline 8 & 9.374 & 0.1601 & 9.815 & 0.9813 & 0.0035 & 13.605 & 0.9796 \\
\hline
\end{tabular}

3.7. Biosorption Isotherms. Isotherm studies were performed in a batch mode using concentrations of hexavalent chromium ranging from 6 to $19 \mathrm{mg} / \mathrm{L}$ at different solution $\mathrm{pH}$. Two equilibrium models, namely, the Langmuir and the Freundlich were used to analyze the data. The linear form of the Langmuir isotherm model is given by the following:

$$
\frac{C_{\mathrm{e}}}{q_{\mathrm{e}}}=\frac{C_{\mathrm{e}}}{Q_{\mathrm{m}}}+\frac{1}{Q_{\mathrm{m}} b},
$$

where $q_{e}$ and $C_{e}$ are the equilibrium concentrations of chromium in the sorbent $(\mathrm{mg} / \mathrm{g})$ and liquid phase $(\mathrm{mg} / \mathrm{L})$ respectively. $Q_{\mathrm{m}}$ and $b$ are the Langmuir constants which are related to the sorption capacity and energy of sorption, respectively. These values can be calculated from the intercept and slope of the linear plot, with $C_{\mathrm{e}} / q_{\mathrm{e}}$ versus $C_{\mathrm{e}}$.

The linear form of the Freundlich isotherm model can be expressed as follows:

$$
\log q_{\mathrm{e}}=\log k_{\mathrm{F}}+\frac{1}{n} \log C_{\mathrm{e}}
$$

where $q_{\mathrm{e}}$ and $C_{\mathrm{e}}$ are the equilibrium concentration of chromium in the biosorbent $(\mathrm{mg} / \mathrm{g})$ and liquid phase $(\mathrm{mg} / \mathrm{L})$, respectively. $k_{\mathrm{F}}$ and $n$ are the Freundlich constants which are related to sorption capacity and intensity, respectively. These constants can be calculated from the slope and intercept of the linear plot, with $\log q_{\mathrm{e}}$ versus $\log C_{\mathrm{e}}$.
The isotherms constants calculated from the slope and intercept of Figure 9 for Langmuir and Figure 10 for Freundlich are presented in Table 2. According to regression coefficients, the experimental data fit well both Freundlich $\left(R^{2}=0.9871-0.9982\right)$ and Langmuir models $\left(R^{2}=0.9029-\right.$ $0.9969)$, suggesting that both monolayer and heterogeneous surface sorption affect the biosorption of $\mathrm{Cr}(\mathrm{VI})$ [31]. Similar mechanisms of Cr(VI) sorption onto biosorbent has also been reported by other studies [9]. The separation factor, an indicator of the reliability of the biosorption, is defined by the following equation:

$$
R=\frac{1}{1+b C_{0}},
$$

where $C_{0}$ is the initial $\operatorname{Cr}(\mathrm{VI})$ concentration and $b$ is the Langmuir isotherm constant.

The value of $R$ varied from 0.14 to 0.90 . These values are less than 1, indicating the favorable biosorption of $\mathrm{Cr}(\mathrm{VI})$ on Grewia spp. biopolymer [31]. Moreover, the " $n$ " values lie between 1 and 10, which shows that biosorption is beneficial [25].

\section{Conclusion}

Biosorption of hexavalent chromium onto Grewia spp. biopolymer has been studied in detail. Grewia spp. biopolymer is negatively charged and is able to remove $98 \%$ of 


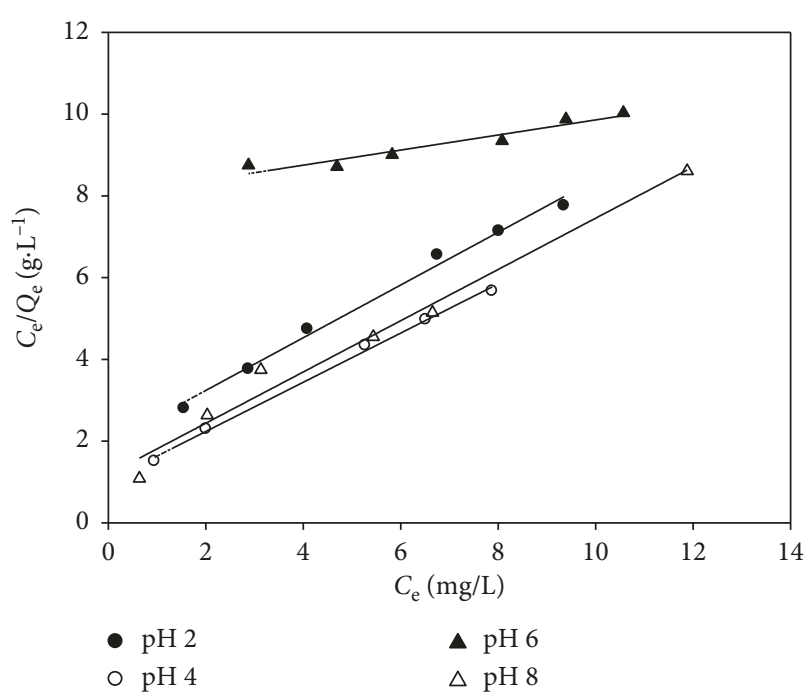

Figure 9: Langmuir plots for Cr(VI) biosorption by Grewia spp. biopolymer. Contact time $60 \mathrm{~min}, T=25 \pm 2^{\circ} \mathrm{C}$.

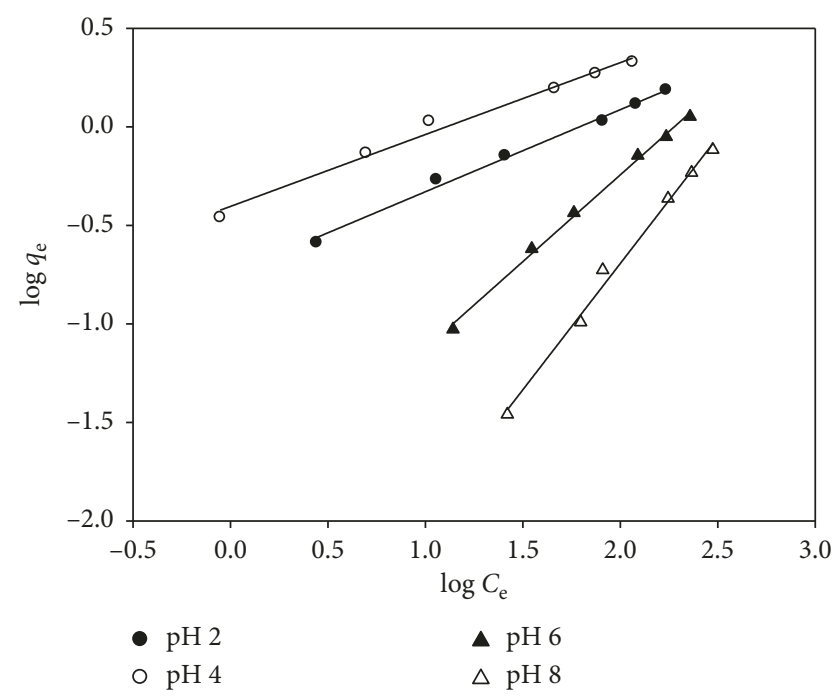

FIgURe 10: Freundlich plots for Cr(VI) biosorption by Grewia spp. biopolymer. Contact time $60 \mathrm{~min} ; \mathrm{T}=25 \pm 2^{\circ} \mathrm{C}$.

TABLE 2: Langmuir and Freundlich isotherms parameters for $\mathrm{Cr}(\mathrm{VI})$ biosorption on Grewia spp. biopolymer.

\begin{tabular}{lcccc}
\hline Isotherm model & $\mathrm{pH} 2$ & $\mathrm{pH} 4$ & $\mathrm{pH} \mathrm{6}$ & $\mathrm{pH} \mathrm{8}$ \\
\hline Langmuir & & & & \\
$Q_{\max }$ & 1.555 & 1.661 & 5.258 & 1.613 \\
$b$ & 0.331 & 0.584 & 0.240 & 0.52 \\
$R^{2}$ & 0.9919 & 0.9969 & 0.9356 & 0.9029 \\
\hline Freundlich & & & & \\
$k_{\mathrm{F}}$ & 1.516 & 1.441 & 2.409 & 3.649 \\
$n$ & 2.402 & 2.738 & 1.137 & 0.984 \\
$R^{2}$ & 0.9936 & 0.9871 & 0.9967 & 0.9982 \\
\hline
\end{tabular}

hexavalent chromium. Equilibrium was attained within $50 \mathrm{~min}$, regardless of the $\mathrm{pH}$ studied. The amount of chromium biosorbed was affected by the $\mathrm{pH}$ of the solution. This amount increases with the increase of biosorbent dose and initial chromium concentration. Kinetics studies revealed that the pseudo-first-order model described well the $\mathrm{Cr}(\mathrm{VI})$ biosorption, which suggests that the process is of physical nature. Both Langmuir and Freundlich isotherms fit the biosorption data adequately. Being an inexpensive and abundantly available material, Grewia spp. biopolymer is a potential biosorbent for the elimination of $\mathrm{Cr}(\mathrm{VI})$ from aqueous solutions.

\section{Data Availability}

The data used to support the findings of this study are available from the corresponding author upon request.

\section{Conflicts of Interest}

The authors declare that they have no conflicts of interest.

\section{Acknowledgments}

The authors are grateful to ENSAI for supporting this research.

\section{Supplementary Materials}

These data were used to plot curves shown in figures. (Supplementary Materials)

\section{References}

[1] S. M. Samuel, M. E. A. Abigail, and R. Chidambaram, "Isotherm modelling, kinetic study and optimization of batch parameters using response surface methodology for effective removal of $\mathrm{Cr}(\mathrm{VI})$ using fungal biomass," PLoS One, vol. 10, no. 3, Article ID e0116884, 2015.

[2] W. Li, X. Gong, X. Li, D. Zhang, and H. Gong, "Removal of $\mathrm{Cr}(\mathrm{VI})$ from low-temperature micro-polluted surface water by tannic acid immobilized powdered activated carbon," Bioresource Technology, vol. 113, pp. 106-113, 2012.

[3] Z. A. Al-Othman, R. Ali, and Mu. Naushad, "Hexavalent chromium removal from aqueous medium by activated carbon prepared from peanut shell: adsorption kinetics, equilibrium and thermodynamic studies," Chemical Engineering Journal, vol. 184, pp. 238-247, 2012.

[4] A. Gaffer, A. A. Al Kahlawy, and D. Aman, "Magnetic zeolitenatural polymer composite for adsorption of chromium (VI)," Egyptian Journal of Petroleum, vol. 26, no. 4, pp. 995-999, 2017.

[5] I. J. Puentes-Cardenas, A. M. Pedroza-Rodríguez, M. Navarrete-Lopez, T. L. Villegas-Garrido, and E. CristianiUrbina, "Biosorption of trivalent chromium from aqueous solutions by Pleurotus ostreatus biomass," Environmental Engineering and Management Journal, vol. 11, no. 10, pp. 1741-1752, 2012.

[6] A. Verma, S. Chakraborty, and J. K. Basu, "Adsorption study of hexavalent chromium using tamarind hull-based adsorbents," Separation and Purification Technology, vol. 50, no. 3, pp. 336-341, 2006.

[7] R. Rakhunde, L. Deshpande, and H. D. Juneja, "Chemical speciation of chromium in water: a review," Critical Reviews in Environmental Science and Technology, vol. 42, no. 7, pp. 776-810, 2012. 
[8] H. Katsumata, S. Kaneco, K. Inomata et al., "Removal of heavy metals in rinsing wastewater from plating factory by adsorption with economical viable materials," Journal of Environmental Management, vol. 69, no. 2, pp. 187-191, 2003.

[9] N. A. Fathy, S. T. El-Wakeel, and R. R. Abd El-Latif, "Biosorption and desorption studies on chromium (VI) by novel biosorbents of raw rutin and rutin resin," Journal of Environmental Chemical Engineering, vol. 3, no. 2, pp. 1137-1145, 2015.

[10] R. Aravindhan, A. Fathima, M. Selvamurugan, J. R. Rao, and U. N. Balachandran, "Adsorption, desorption, and kinetic study on $\mathrm{Cr}$ (III) removal from aqueous solution using Bacillus subtilis biomass," Clean Technologies and Environmental Policy, vol. 14, no. 4, pp. 727-735, 2012.

[11] V. T. P. Vinod, R. B. Sashidhar, and B. Sreedhar, "Biosorption of nickel and total chromium form aqueous solution by gum kondagogu (Cochlospermum gossypium): a carbohydrate biopolymer," Journal of Hazardous Materials, vol. 178, no. 1-3, pp. 851-860, 2012.

[12] V. J. P. Vilar, J. A. B. Valle, A. Bhatnagar et al., "Insights into trivalent chromium biosorption onto protonated brown algae Pelvetia canaliculata: distribution of chromium ionic species on the binding sites," Chemical Engineering Journal, vol. 200-202, pp. 140-148, 2012.

[13] T. A. Davis, B. Volesky, and A. Mucci, "A review of the biochemistry of heavy metal biosorption by brown algae," Water Research, vol. 37, no. 18, pp. 4311-4330, 2003.

[14] K. S. Ndi, G. P. Kofa, N. M. B. Kameni, and G. J. Kayem, "Diffusion coefficients of Grewia spp. biopolymers in water," African Journal of Environmental Science and Technology, vol. 9, no. 4, pp. 317-324, 2015.

[15] S. A. Osemeahon, A. M. Kolo, I. J. Opara, and A. Hamma, "Bioremediation of wastewater with immobilized dargaza (Grewia mollis): effect of some physical properties," IOSR Journal of Applied Chemistry, vol. 9, pp. 37-43, 2016.

[16] P. Somboonpanyakul, Q. Wang, W. Cui, S. Barbut, and P. Jantawat, "Malva nut gum. (part I): extraction and physicochemical characterization," Carbohydrate Polymers, vol. 64, no. 2, pp. 247-253, 2006.

[17] L. S. Clesceri, A. E. Greenberg, and A. D. Eaton, Standard Methods for the Examination of Water and Wastewater, American Public Health Association, Washington, DC, USA, 1998.

[18] M. A. Mohammadifar, S. M. Musavi, A. Kiumarsi, and P. A. Williams, "Solution properties of targacanthin (watersoluble part of gum tragacanth exudate from Astragalus gossypinus)," International Journal of Biological Macromolecules, vol. 38, no. 1, pp. 31-39, 2006.

[19] E. Malkoc, Y. Nuhoglu, and M. Dundar, "Adsorption of chromium(VI) on pomace-an olive oil industry waste: batch and column studies," Journal of Hazardous Materials, vol. 138, no. 1, pp. 142-151, 2006.

[20] A. Esposito, F. Pagnanelli, A. Lodi, C. Solisio, and F. Veglio, "Biosorption of heavy metals by Sphaerotilus natans: an equilibrium study at different $\mathrm{pH}$ and biomass concentrations," Hydrometallurgy, vol. 60, no. 2, pp. 129-141, 2001.

[21] I. Ullah, R. Nadeem, M. Iqbal, and Q. Manzoor, "Biosorption of chromium onto native and immobilized sugarcane bagasse waste biomass," Ecological Engineering, vol. 60, pp. 99-107, 2013.

[22] A. H. M. G. Hyder, S. A. Begum, and N. O. Egiebor, “Adsorption isotherm and kinetic studies of hexavalent chromium removal from aqueous solution onto bone char," Journal of Environmental Chemical Engineering, vol. 3, no. 2, pp. 1329-1336, 2015.
[23] I. Enniya, L. Rghioui, and A. Jourani, "Adsorption of hexavalent chromium in aqueous solution on activated carbon prepared from apple peels," Sustainable Chemistry and Pharmacy, vol. 7, pp. 9-16, 2018.

[24] M. Imamoglu and O. Tekir, "Removal of copper (II) and lead (II) ions from aqueous solutions by adsorption on activated carbon from a new precursor hazelnut husks," Desalination, vol. 228, no. 1-3, pp. 108-113, 2008.

[25] M. R. Gopal Reddi, T. Gomathi, M. Saranya, and P. N. Sudha, "Adsorption and kinetic studies on the removal of chromium and copper onto Chitosan-g-maliec anhydride-g-ethylene dimethacrylate," International Journal of Biological Macromolecules, vol. 104, pp. 1578-1585, 2017.

[26] L. Zhang and Y. Zhang, "Adsorption characteristics of hexavalent chromium on $\mathrm{HCB} / \mathrm{TiO}_{2}$," Applied Surface Science, vol. 316, pp. 649-656, 2014.

[27] Y. S. Ho and G. McKay, "The sorption of lead(II) ions on peat," Water Research, vol. 33, no. 2, pp. 578-584, 1999.

[28] J. Chwastowski, P. Staroń, H. Kołoczek, and M. Banach, "Adsorption of hexavalent chromium from aqueous solutions using Canadian peat and coconut fiber," Journal of Molecular Liquids, vol. 248, pp. 981-989, 2017.

[29] S. K. Maji, A. Pal, and T. Pal, "Arsenic removal from real-life groundwater by adsorption on laterite soil," Journal of Hazardous Materials, vol. 151, no. 2-3, pp. 811-820, 2008.

[30] F. Mutongo, O. Kuipa, and P. K. Kuipa, "Removal of Cr(VI) from aqueous solutions using powder potato peelings as a low cost sorbent," Bioinorganic Chemistry and Applications, vol. 2014, Article ID 973153, 7 pages, 2014.

[31] M. Mahramanlioglu, I. Kizilcikli, and I. O. Bicer, “Adsorption of fluoride from aqueous solution by acid treated spent bleaching earth," Journal of Fluorine Chemistry, vol. 115, no. 1, pp. 41-47, 2002. 

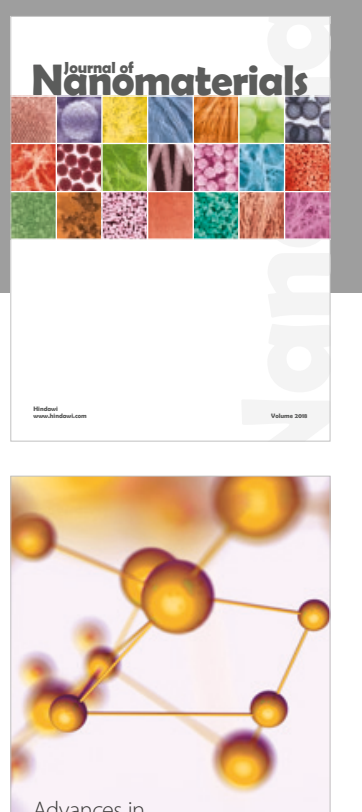

Physical Chemistry
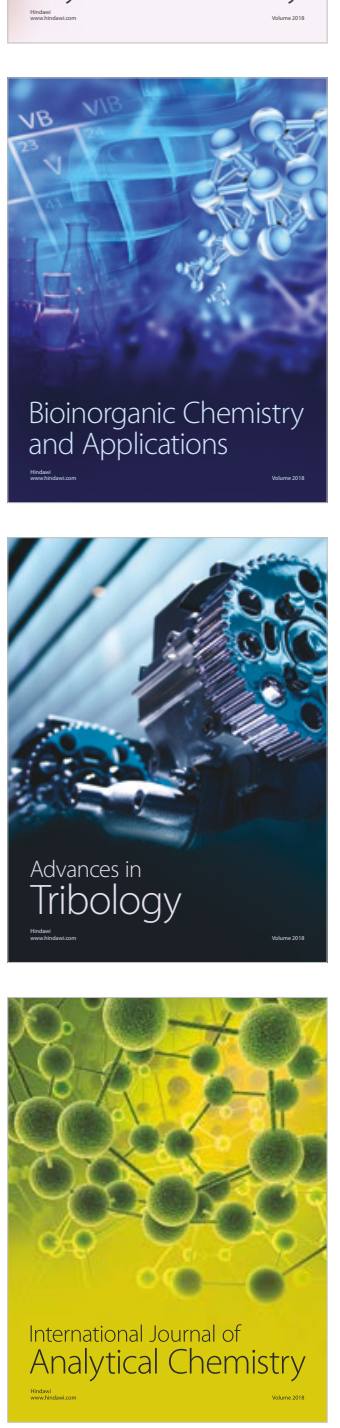

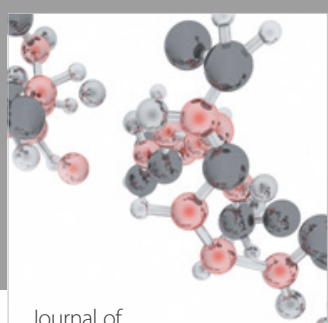

Analytical Methods

in Chemistry

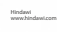

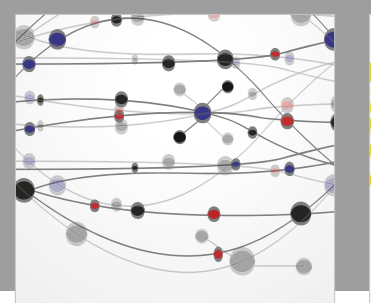

The Scientific World Journal

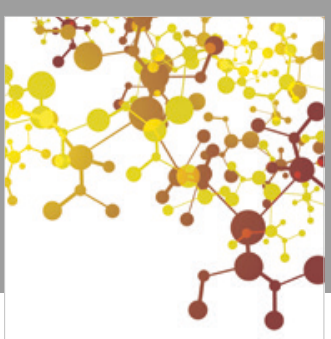

Journal of

Applied Chemistry
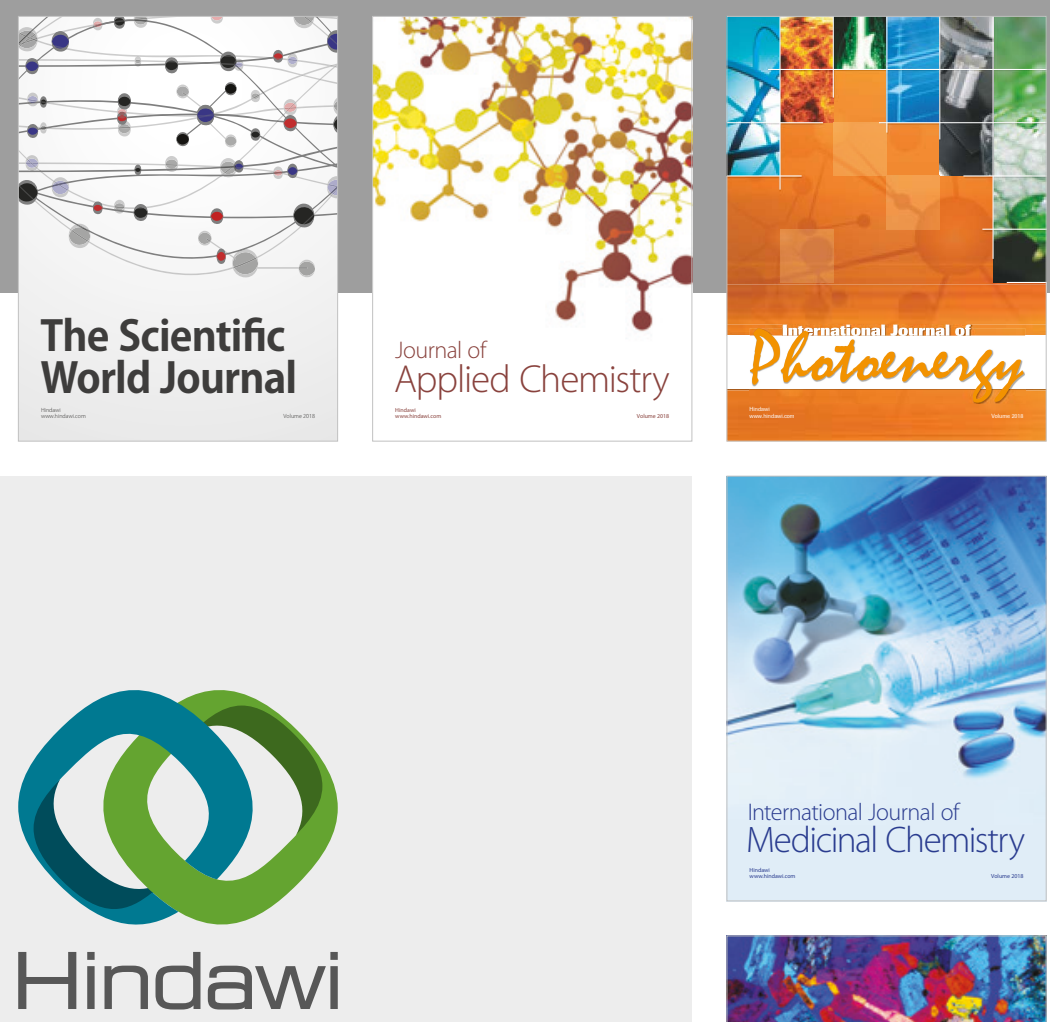

Submit your manuscripts at

www.hindawi.com
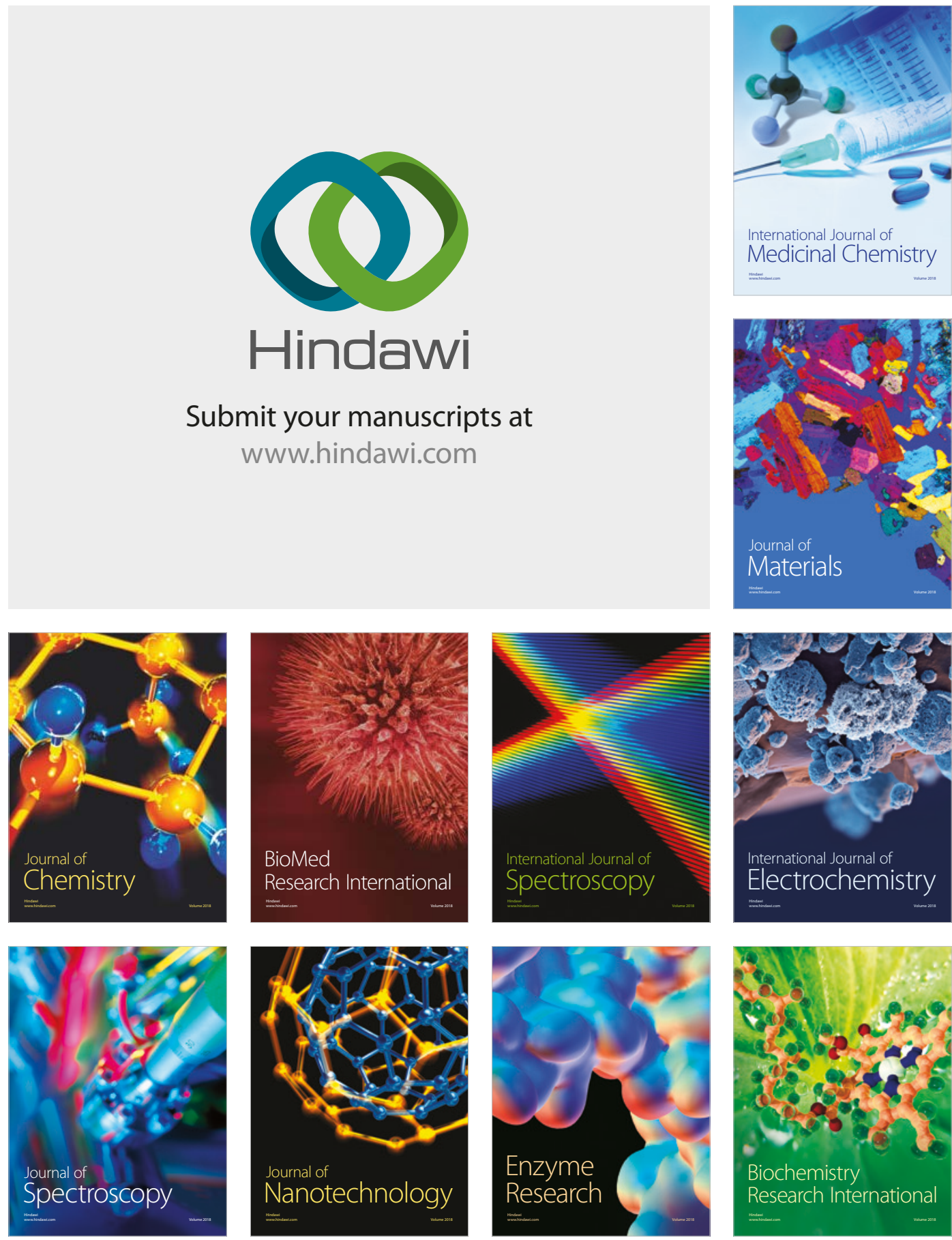
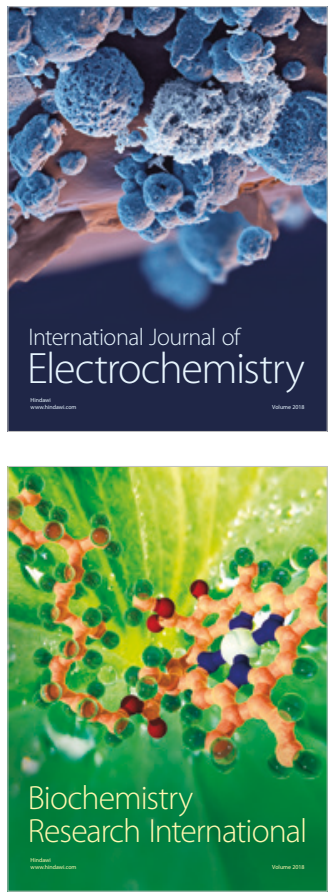